\title{
Os componentes da identidade de marca de Gramado/Brasil que geram sua imagem de "destino turístico modelo" e os relacionamentos da marca com os stakeholders internos
}

\author{
The brand identity of Gramado, Brazil, that generates the image of a \\ "tourism destination model" and the brand relationships with inter- \\ nal stakeholders
}

\section{Los componentes de la identidad de marca de Gramado/Brasil que generan su imagen de "destino turístico modelo" y las relaciones de la marca com los stakeholders internos}

\author{
Vanessa Acosta de Azambuja ${ }^{1}$ \\ Marlei Salete Mecca $^{2}$
}

\begin{abstract}
Resumo: Esta pesquisa objetiva descrever os componentes da identidade de marca de Gramado/Brasil que geram sua imagem de "destino turístico modelo", assim como verificar se há fortes relacionamentos entre a marca e os stakeholders internos dessa destinação. A principal teoria utilizada neste estudo é o modelo "rede relacional da marca" de Hankinson (2004). Sendo um estudo de caso, são realizadas entrevistas e consultadas outras fontes de evidência, como uma dissertação e uma reportagem. Integraram o universo da pesquisa sujeitos do Poder Público, da iniciativa privada, dos trabalhadores e da comunidade local de Gramado, totalizando 21 entrevistados. Os procedimentos organizativos e analíticos dos dados discursivos pautam-se por supostos e técnicas da análise de conteúdo. Dentre os resultados, está que os atributos com maior ocorrência nas respostas dos entrevistados são os simbólicos e os funcionais, destacando-se atrativos/eventos turísticos como aquilo que diferencia Gramado de seus concorrentes. Também, é constatada a falta de um planejamento estratégico com a participação ativa dos stakeholders internos.
\end{abstract}

Palavras-chave: Destinação turística. Identidade de marca. Relacionamentos. Gramado.

Abstract: This research aims to describe the components of Gramado/Brazil brand identity that generate its "tourist destination model" image, and to verify if there are strong relationships between the brand and the internal stakeholders of this destination. The main theory used in this study is the "relational network brand"

1 Universidade de Caxias do Sul (UCS). Caxias do Sul, RS, Brasil. Elaboração do referencial teórico, coleta dos dados, análise dos dados dos dados, redação do trabalho, preparação do artigo científico.

2 Universidade de Caxias do Sul (UCS). Caxias do Sul, RS, Brasil. Orientação na concepção e desenho do trabalho científico, análise dos dados, revisão crítica do trabalho; aprovação final.

Artigo recebido em: 07/03/2016. Artigo aprovado em: 06/10/2016. 
model by Hankinson (2004). This is a descriptive and qualitative study. It is a case study, using interviews and documentary resources such as a dissertation and a report. The research universe is composed of government individuals, the private sector, the employees and the local community of Gramado, in a total of 21 respondents. Organizational and analytical procedures of discursive data are guided by assumptions and techniques of content analysis. Among the results it stands out that symbolic and functional attributes have the highest occurrence in the answers of respondents. Particularly, tourist attractions/events are what differentiates Gramado from its competitors. Also, Gramado lacks a strategic planning and active participation of internal stakeholders.

Keywords: Tourism destination. Brand identity. Relationships. Gramado.

Resumen: Esta investigación tiene como objetivo describir los componentes de la identidad de marca de Gramado/Brasil que generan su imagen de "destino turístico modelo", así como la verificación de relaciones fuertes entre la marca y los stakeholders internos de ese destino. La principal teoria utilizada en este estudio es el modelo "red relacional de la marca" de Hankinson (2004). Siendo um caso de estudio, son realizadas entrevistas y consultadas otras fuentes de prueba, como una tesis de maestría y un artículo. Integraran el universo de la investigación sujetos del gobierno, del sector privado, de los trabajadores y de la comunidad local de Gramado, un total de 21 entrevistados. Los procedimientos de organización y de análisis de datos discursivos se guían por los supuestos y técnicas de la análisis de contenido. Entre los resultados está que los atributos de mayor ocurrencia en las respuestas de los encuestados son los simbólicos y los funcionales, destacando atracciones/eventos turísticos como lo que diferencia Gramado de sus competidores. También se observa la falta de planificación estratégica con la participación activa de los stakeholders internos.

Palavras-clave: Destino turístico. Identidad de marca. Relaciones. Gramado.

\section{INTRODUÇÃO}

Esta pesquisa objetiva descrever os componentes da identidade de marca de Gramado/Brasil que geram sua imagem de "destino turístico modelo", e verificar se há fortes relacionamentos entre a marca e os stakeholders internos desse destino. Esses objetivos foram delimitados a partir da observação de que o Ministério do Turismo do Brasil (MTur), outros destinos brasileiros e internacionais, e os turistas têm essa imagem de Gramado - como é exposto nos próximos parágrafos -, e da relação encontrada, a partir da pesquisa bibliográfica, entre identidade e imagem de marca.

Conforme está no Relatório final - Vivências Brasil: aprendendo com o turismo nacional 2008/2009 do projeto Benchmarking em Turismo, iniciativa do MTur, Gramado é "[...] modelo em gestão e referência no turismo nacional" (MTur, 2008, p. 50). No relatório, destacam-se as políticas públicas no turismo, envolvendo discussão sobre o Plano Diretor municipal e a infraestrutura turística, que inclui limpeza urbana e banheiros. Ainda realçam-se as parcerias públicoprivadas na realização dos principais eventos de Gramado e a gestão do Natal Luz pela inovação e inclusão da comunidade. Nova etapa do projeto foi realizada em Gramado em 2010, propiciando aos participantes "[...] contato com boas práticas relacionadas à estruturação e gestão de eventos temáticos como estratégia para redução da sazonalidade e ainda o recurso de tematização como diferencial [...]". (MTur, 2010, p. 4).

Em outras ocasiões, gestores de diversos lugares se dirigem a Gramado para realizar benchmarking. Por exemplo, a irmandade existente entre Gramado e Óbidos/Portugal viabiliza benchmarking sobre o Natal Luz e outros eventos turísticos (PMG, 2008). Com relação ao Natal Luz, Gramado foi visitada por comitiva de Bragança Paulista/Brasil em 2013 (PMG, 2013a); pelo Prefeito de Iguape/Brasil em 2014 (PMG, 2014a); 
pela Prefeita de Ourinhos/Brasil em 2014 (PMG, 2014b). Ainda, em 2013, foram recebidas autoridades de Caldas Novas/Brasil que consideram Gramado um bem sucedido modelo de turismo e de gestão pública (Secom, 2013). No mesmo ano, o embaixador da Nigéria no Brasil visitou a destinação para conhecer um pouco da economia voltada ao turismo (PMG, 2013b). Durante o Festival de Turismo de Gramado em 2013, uma comitiva do Chile visitou a Prefeitura Municipal para coIher informações sobre infraestrutura, atrativos turísticos e eventos (PMG, 2013c).

Gramado ainda é considerado "destino turístico modelo" pelos turistas. A destinação foi premiada como Melhor Destino de Inverno do Brasil em 2010, 2011 e 2012, e de Melhor Cidade Turística do Brasil em 2011 e 2012, pela Revista Viagem e Turismo, a partir de pesquisas realizadas com os leitores dessa revista. (PMG, 2013d).

\section{CONCEITOS E MODELOS TEÓRICOS}

Para Reynolds (1965), imagem é a construção mental do turista baseada em poucas impressões escolhidas a partir de muitas informações de um destino turístico. Kotler \& Gertner (2002) afirmam que há ativação de uma imagem de um país na mente das pessoas ao apenas mencionar-se o seu nome, mesmo na ausência de atividades para gerir uma marca consciente.

Já marca, segundo a American Marketing Association, é um nome, termo, sinal, símbolo ou desenho, ou combinação desses, para identificar os produtos/serviços e diferenciá-los dos concorrentes (Kotler, 1997). Mas, para Pimentel, Pinho \& Vieira (2006, p. 286), “a marca não se limita a um nome numa etiqueta, mas cria e agrega um valor de consumo perceptível ao consumidor". Com as marcas, a utilidade do produto não se limita a sua funcionalidade, unindo a isso os mundos de significações incorporados a esse (Norberto, 2004). Assim, entende-se que a marca é um nome, um sinal, um símbolo ou um desenho com um mundo de significações, que cria e agrega um valor de consumo perceptível ao consumidor. Ainda, a marca está inscrita em um campo simbólico surgido a partir de uma estratégia por intervenção profissional, utilizando o real, a fim de criar vantagem competitiva no mercado (Norberto, 2007). Karamarko (2010) completa que a marca indica a identidade de uma destinação.

Segundo Meler \& Ruzic (1999), identidade é um conjunto de características que fazem de alguém o que é. Quanto à identidade de marca especificamente, representa as associações que a marca deseja gerar na mente dos consumidores (Karamarko, 2010). Aaker (1996) afirma que a identidade de marca representa a autoimagem e a imagem aspirada no mercado de um produto. Assim, entende-se que a identidade da marca de destinos turísticos é formada pelas suas características, as quais os stakeholders internos percebem e desejam transmitir, a fim de gerar a imagem que cobiçam na mente do turista. Pimentel, Pinho \& Vieira (2006) observam que a imagem é um conceito ligado com o receptor, já a identidade está associada ao emissor.

De acordo com Aaker (1996), as características da identidade de marca não se limitam aos atributos do produto, propondo 4 perspectivas da identidade de marca: a marca como produto; a marca como organização; a marca como pessoa; e a marca como símbolo. Quanto à perspectiva marca como produto, fazem parte: âmbito, atributos, qualidade/valor, usos, usuários, e país de origem do produto. Âmbito é a associação de uma marca com uma classe de produtos, de forma que o cliente chame a classe pelo nome da marca. Atributos são as características de um produto que proporcionem benefícios ao cliente. A qualidade é um atributo tão relevante que é considerado separadamente e está relacionado ao valor, visto que esse último enriquece o conceito, acrescentando a dimensão preço. Usos se refere à exclusividade de uma determinada utilização 
ou aplicação que algumas marcas detêm. Uma marca também pode ser posicionada conforme $o$ tipo de usuários. E, por último, pode-se vincular uma marca a um país de origem, que lhe dará credibilidade. (Aaker, 1996)

Com relação à marca como organização, essa perspectiva inclui atributos organizacionais, e local versus global. Os atributos da organização são mais difíceis de copiar que do produto, visto que envolvem pessoas, cultura, valores e programas organizacionais, ou seja, aspectos menos tangíveis que os atributos do produto. Referindose ao local versus global, quando uma marca opta por ser reconhecida como local, destaca sua relação com a tradição para o segmento de mercado de um lugar, na busca de formar um vínculo com os clientes e de expressar orgulho. Desse modo, uma marca local pode mostrar-se mais compreensiva às necessidades e atitudes da localidade. Já quando uma marca escolhe atuar como global, possibilita o prestígio e a certeza de ser detentora de um público e de uma missão maiores, e projetar uma personalidade cosmopolita. Uma marca global, em geral, sinaliza que é avançada em tecnologia, capaz de investir em Pesquisa e Desenvolvimento, e de seguir os avanços realizados nos países onde concorre. O papel da marca como organização é propiciar credibilidade a seus produtos ou às suas submarcas de produtos. (Aaker, 1996).

Já marca como pessoa abarca: personalidade da marca; relacionamentos marca-cliente. Tal como uma pessoa, a marca pode apresentar adjetivos. Ainda, a personalidade da marca pode constituir a base do relacionamento marca-cliente (Aaker, 1996). De Chernatony (1999) também associa os relacionamentos com a personalidade, acrescentando os relacionamentos entre funcionários, entre funcionários e clientes, e entre funcionários e outros stakeholders.

E marca como símbolo envolve imagens visuais/metáforas e tradição da marca. Os símbolos, como uma figura, uma cor, um design do pro- duto, facilitam a obtenção de reconhecimento e recordação. (Aaker, 1996).

Karamarko (2010) acredita que a teoria de Aaker é aplicável no turismo. Entretanto, para Hankinson (2007), há importantes características de marcas de destinos que as distinguem das marcas de produtos e que essas levam a diferenças na maneira como marcas de destinos são criadas, desenvolvidas e mantidas. Essas características são: 1) coprodução - como há uma amálgama de serviços individuais em uma destinação turística, o produto lugar é coproduzido por todos; 2) coconsumo - devido à natureza multifacetada do produto lugar, ele é consumido simultaneamente por diferentes clientes para diferentes fins; 3 ) variabilidade - cada experiência do consumidor de produto-lugar é montada individualmente a partir da variedade de serviços e experiências em oferta; 4) definição legal dos limites do lugar - os limites de um lugar são definidos legalmente pelos governos, o que, às vezes, dificulta a oferta de um produto significativo que combine dois ou mais locais; 5) sobreposição administrativa - ocorre quando há divergências entre, por exemplo, a marca cidade e a marca regional, podendo causar confusão na mente dos turistas; 6 ) e responsabilidade política - em se tratando de lugares, a responsabilidade desses recai sobre o Poder Público, cujos membros podem ser modificados a cada eleição, o que pode resultar em decisões inconsistentes com objetivos a longo prazo. Parkerson \& Saunders (2005) expõem que a marca de destinações turísticas também se difere da marca de organizações. Para esses autores, diferentemente de uma corporação, uma cidade não tem estrutura organizacional convergindo em um único foco.

Considerando as diferenças apontadas entre marcas de destinos turísticos e as marcas em geral, em 2004, Hankinson já havia exibido um modelo teórico específico de identidade de marca de destinações (Figura 1), em que conceituou marca como relacionamentos. Desse modo, 
a marca é detentora de uma personalidade que Ihe permite formar relacionamento com o consumidor. Em se tratando de serviços, há interação entre os prestadores de serviços e os consumidores, e o encontro entre eles é uma oportunidade para o desenvolvimento de uma relação real, através do fornecimento de uma experiência positiva. Para isso, ainda é necessário o relacionamento da marca com os demais stakeholders.

Hankinson (2004) afirma que o produtoexperiência não pode ser controlado como um produto manufaturado. O consumidor é livre para escolher quais elementos do produto local deseja consumir. Sendo uma destinação complexa em público e stakeholders, é preciso que o branding (criação e gestão estratégica de marca) seja coordenado, não gerenciado. Nisso está a relevância da marca como relacionamentos.

Desse modo, seu modelo, denominado rede relacional da marca, é formado por um núcleo e por 4 categorias de relacionamentos de marca. O núcleo representa a identidade de marca de um lugar e é composto por personalidade, posicionamento e realidade. Já as 4 categorias de relacionamentos são: com os serviços pri mários, com a infraestrutura da marca, com os meios de comunicação, e com os consumidores.

Descrevendo o núcleo da marca, Hankinson expôs que a personalidade é caracterizada pelos atributos funcionais (tangíveis, que satisfazem necessidades utilitárias e ambientais); simbólicos (intangíveis, que satisfazem necessidades de aprovação social, expressão pessoal e autoestima) e experienciais (vinculados aos atributos funcionais e simbólicos juntos e que descrevem como a experiência vivenciada pelo turista o faz sentir). Já o posicionamento da marca trata-se da identificação dos atributos que diferenciem o destino turístico de outros lugares. A realidade da marca é o que deve garantir que tanto a personalidade como o posicionamento sejam enraizados na realidade, que a experiência prometida seja cumprida.

Dessa maneira, uma marca bem-sucedida de destino não deve se restringir ao marketing criativo, sendo essencial o seu suporte constituído por investimentos em instalações e serviços essenciais, a fim de reforçar os valores do núcleo da marca.

Observa-se que Hankinson não restringe a construção da identidade de marca ao planejamento do que se deseja comunicar aos turistas, ou seja, à definição da personalidade e do posicionamento a constar na promoção da marca. Mais que isso, Hankinson demonstra concordar com Keller \& Machado (2006, p. 7), cuja visão deles é de que, quando o consumidor confia e é fiel a uma marca, ele espera que lhe proporcionem "[...] utilidade por meio do funcionamento consistente do produto, além de preço, promoção, ações e programas de distribuição adequados". Assim, é relevante incluir estratégias de produto na construção da identidade de marca, para que as instalações e os serviços condigam com o divulgado; estratégias de distribuição, para que o transporte até as instalações e serviços esteja conforme o prometido na divulgação; e estratégias de preço, para garantir que a tarifa cobrada por instalações, serviços e transporte seja coerente com a sua qualidade e com o divulgado.

Então, ao nomear seu modelo de rede relacional da marca e ao constituí-lo em núcleo da marca e 4 categorias de relacionamentos, Hankinson (2004) transmite que a rede de relacionamentos deve ser formada durante todo o processo de construção da identidade de marca. Isso inclui o planejamento, o preparo e a operacionalização. 
Figura 1 - Rede relacional da marca

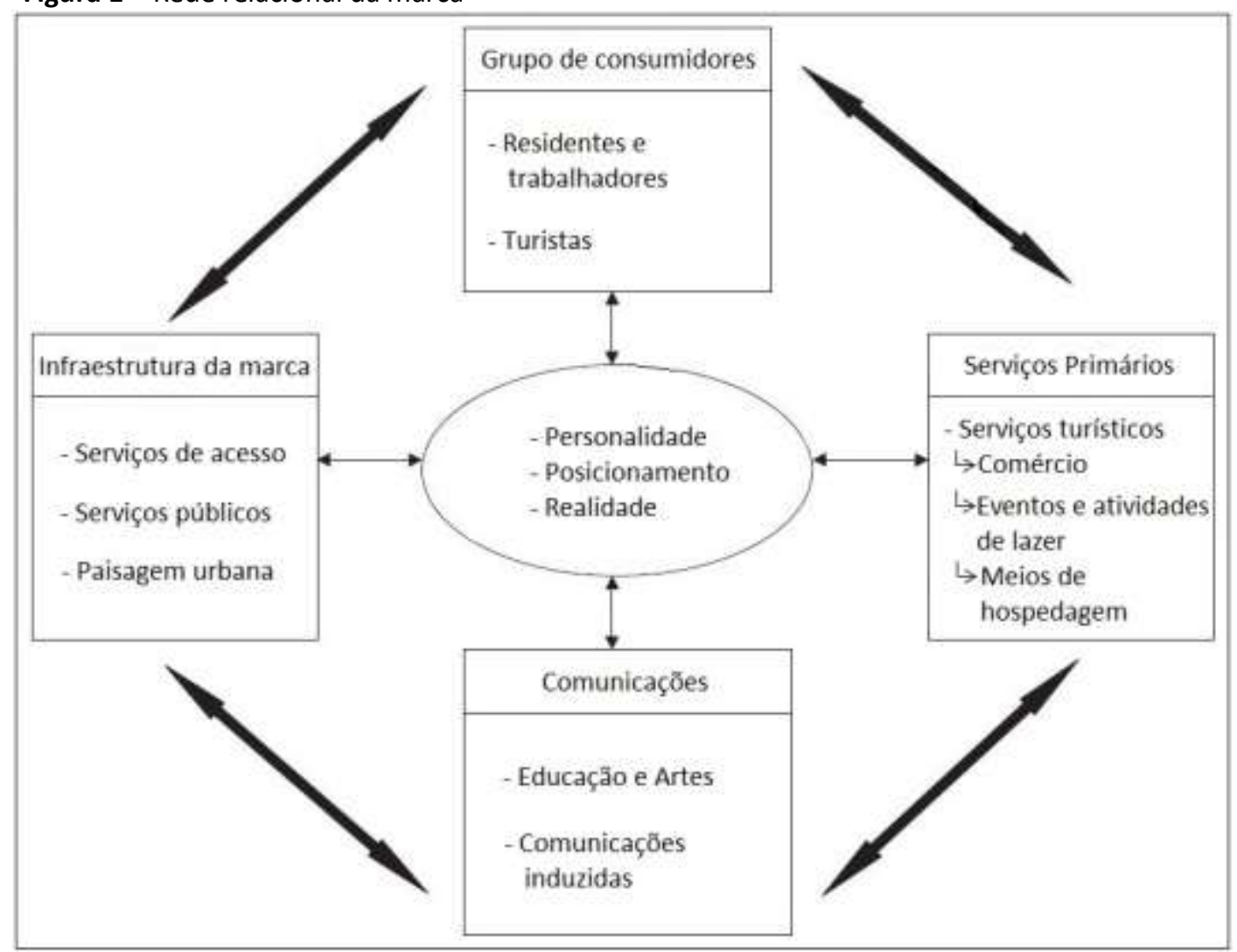

Fonte: Traduzida de Hankinson (2004)

Quanto às 4 categorias de relacionamentos, os serviços primários referem-se aos comerciantes, eventos e atividades de lazer, hotéis e suas associações. A infraestrutura da marca é composta por: provedores de acesso (transporte interno e para a destinação), gestores de instalações públicas (banheiros, limpeza de ruas, estacionamentos) e brandscape (ambiente construído onde estão os serviços que fazem parte do núcleo marca). Os meios de comunicação incluem as comunicações orgânicas (artes e educação) e as comunicações induzidas (propaganda, publicidade e relações públicas). Dos consumidores fazem parte os visitantes (cujos públicos-alvo não devem ser conflitantes); os moradores (devendo haver compatibilidade entre o turismo e os interesses da comunidade) e os funcionários das empresas locais.
Hankinson (2004) conclui que nunca houve tanta necessidade de estudos que incluam um modelo abrangente de marca-lugar e que se baseie na realidade da marca. A necessidade se dá ao aumento da concorrência entre destinos e à existência de um ambiente onde há mais aversão a riscos e consciência de segurança.

\section{PROCEDIMENTOS METODOLÓGICOS}

Este estudo se caracteriza como descritivo qualitativo. Quanto ao método, enquadra-se como estudo de caso. Sendo uma das características do estudo de caso a não restrição a uma fonte de evidência na coleta dos dados, se utiliza, como técnicas de coleta, entrevistas com os stakeholders internos (sendo a identidade de marca um conceito associado ao emissor) e fon- 
tes de pesquisa complementares. Nas entrevistas, abrangem-se diferentes grupos de sujeitos: setor público; setor privado; comunidade local e trabalhadores. Dentre as fontes de pesquisa complementares estão a dissertação de Vargas (2003), em que Gramado é o cenário da pesquisa, e uma reportagem associada ao objeto de estudo. Isso permite uma triangulação, que tem como vantagem o desenvolvimento de linhas convergentes de pesquisa, fazendo com que os resultados sejam mais convincentes e acurados (Yin, 2010).

Entrevistou-se 21 sujeitos, visto que "Na pesquisa qualitativa a preocupação do pesquisador não é com a representatividade numérica do grupo pesquisado, mas com o aprofundamento da compreensão de um grupo social, de uma organização, de uma instituição, de uma trajetória etc." (Goldenberg, 2004, p.14). Chegou-se a esse número a partir do exposto a seguir. Inicialmente, procurou-se entrevistar os sujeitos alvos do programa de benchmarking do MTur, que são os responsáveis por algumas empresas turísticas de Gramado, pela realização dos principais eventos da destinação e pela associação da Casa do Colono. Considerando os stakeholders internos apresentados pelo modelo de Hankinson (2004) - principal teoria utilizada neste estudo -, constatou-se a necessidade de também entrevistar sujeitos da comunidade local, trabalhadores do turismo e responsáveis pela infraestrutura (Poder Público). Porém, algumas das empresas alvos do programa de benchmarking não puderam ou se negaram às entrevistas. Por isso, decidiu-se entrevistar, além de membros das empresas que concordaram em participar da pesquisa, os representantes de todas as entidades de classe ligadas às empresas turísticas de Gramado. Seguindo o critério de entrevistar sujeitos representantes de certo grupo, resolveu-se entrevistar representantes das 9 associações de bairro de Gramado, apesar de conseguido contato com apenas
4 deles. Ainda, entrevistou-se um representante da entidade de classe dos trabalhadores.

A principal teoria utilizada neste estudo é o modelo rede relacional da marca de Hankinson (2004), justificando-se a escolha a seguir. Considerando que uma destinação é um amálgama de produtos e serviços, que proporciona uma experiência total em um lugar, segundo Buhalis (2000), e que, fortes relacionamentos com os stakeholders é a forma que Hankinson (2004) encontrou para uma experiência total bem sucedida, acredita-se ser este um modelo apropriado para caracterizar a identidade de marca da destinação. Esse é o objetivo geral da dissertação de mestrado da primeira autora deste artigo, em que se utilizou o modelo de Hankinson (2004) na íntegra. Porém, devido à alta extensão dos resultados encontrados, neste artigo, é exposto parte desses, que foram investigados a partir de alguns elementos do modelo de Hankinson (2004): seu núcleo e os relacionamentos com os stakeholders internos (Poder Público - infraestrutura da marca; iniciativa privada - serviços primários; trabalhadores e comunidade local - 2 dos integrantes dos consumidores da marca).

Assim, para descrever os componentes da identidade de marca, analisa-se os elementos da identidade de marca indicados por Hankinson (2004): personalidade, posicionamento e realidade. Para isso, fazem-se estas questões: 1) Você acredita que Gramado é um "destino turístico modelo"? 2) Que atributos Gramado tem que o faz "destino turístico modelo"? 3) Quais são os principais destinos turísticos concorrentes de Gramado? 4) Dos atributos citados, quais diferenciam Gramado desses concorrentes? 5) Que tipo de turista frequenta seu estabelecimento e Gramado?

Referente a verificar se há fortes relacionamentos entre a marca e os stakeholders internos (Poder Público, comunidade local, trabalhadores e iniciativa privada), os quais devem compartilhar uma visão comum da identidade da 
marca, isso é viabilizado pela descrição dos componentes da identidade. Hankinson (2004) considera que os moradores e os funcionários das empresas locais também são consumidores da marca. Além disso, através da descrição dos elementos da identidade da marca, é possível constatar se há consenso entre todos os stakeholders internos, o que é um indicativo da formação de fortes relacionamentos entre eles.

Sobre os procedimentos organizativos e analíticos, são pautados em supostos e técnicas da Análise de Conteúdo de Bardin (2004). As técnicas usadas são a análise temática e a análise categorial. Primeiro, realiza-se a análise temática, que trata de identificar os temas que compõem as comunicações dos sujeitos. Ainda realiza-se uma comparação entre as respostas dos 3 grupos de stakeholders encontradas na análise temática. Por fim, faz-se a análise categorial, agrupando-se as unidades de registro (no caso, o tema) em categorias conforme as características em comum (Bardin, 2004), e, neste artigo, baseando-se nas teorias de Hankinson (2004) e Aaker (1996).

\section{RESULTADOS}

Já nas primeiras entrevistas, realizadas com membros da Secretaria Municipal de Turismo de Gramado, verificou-se que a organização do turismo dessa destinação, incluindo o marketing, é sua atribuição. Para Hankinson (2004), referente à marca de destinações, a função de uma entidade é de coordenação em vez de gerência. Isso porque, diferente do visto em uma empresa, cujos setores de produção estão sob o controle da gerência, em uma destinação, o cliente é livre para escolher quais elementos consumir; sendo todos produtos e serviços do amálgama coautores na construção da identidade de marca. Então, mesmo tendo divulgação institucional da destinação, ainda há divulgação e entrega de produtos e serviços pelos componentes do amálgama. Por isso, considera-se as respostas de todos os stakeholders internos.

Em resposta à questão 1 ( Você acredita que Gramado é um "destino turístico modelo"?), todos os sujeitos deram respostas afirmativas. Logo, citaram atributos organizacionais de Gramado (Aaker, 1996), tal como atributos dos produtos e serviços, e atributos vivenciados pelos turistas no local (Hankinson, 2004), em resposta à questão 2 (Que atributos Gramado tem que o faz "destino turístico modelo"?), relatando a personalidade da marca. Assim, com a análise temática sobre os relatos, descobriu-se 34 componentes da identidade de marca de Gramado (Quadro 1).

É pertinente expor que 2 dos sujeitos do Poder Público, 2 da iniciativa privada, e 1 da comunidade local e trabalhadores afirmaram que Gramado é "destino turístico modelo" por um conjunto de fatores. O sujeito 1 (PP) explicita isso: "[...] pode-se encontrar algum detalhe mais bonito noutro lugar, um solto diferenciado, mas o conjunto não. [...] não é uma coisa só, não é uma cascata, é um conjunto.". Para Bahl (2004), a existência de atrativos por si não é suficiente para o turismo, é preciso agregar outros atrativos e combiná-los com facilidades para a permanência e o acesso dos turistas, tornando-os produtos turísticos. O sujeito 7 (IP) comenta que: "Em Gramado tem um conjunto de coisas que vão convergir pra chegar no resultado bom. [...] se recebe muita visita técnica no Natal Luz. [...] copiar uma guirlanda, um boneco de neve [...] fazer igual na cidade dela, mas não terá o nome Gramado por trás.". Isso vai ao encontro do exposto por Kotler (2009), cuja visão é que, caso haja uma "tapeçaria" exclusiva de poderosas estratégias, baseadas em uma configuração única de diversas atividades que se reforçam, os concorrentes podem imitar certos aspectos, mas não toda a "tapeçaria". Para a imitação completa, os concorrentes terão altos gastos e produzirão uma imitação pálida, sem alcançar igual desempenho. 
Quadro 1 - Síntese dos tópicos discursivos identificados nas verbalizações dos sujeitos

\begin{tabular}{|c|c|c|c|c|c|}
\hline \multicolumn{2}{|c|}{ Poder público (PP) } & \multicolumn{2}{|c|}{ Iniciativa privada (IP) } & \multicolumn{2}{|c|}{$\begin{array}{l}\text { Comunidade local e trabalhadores } \\
\text { (CT) }\end{array}$} \\
\hline Tópicos & Freq. & Tópicos & Freq. & Tópicos & Freq. \\
\hline- & - & - & - & $\begin{array}{c}\text { Ameaça à preservação } \\
(-)\end{array}$ & 1 \\
\hline Arquitetura & 2 & Arquitetura & 4 & - & - \\
\hline $\begin{array}{l}\text { Associação com Eu- } \\
\text { ropa }\end{array}$ & 1 & $\begin{array}{l}\text { Associação com Eu- } \\
\text { ropa }\end{array}$ & 5 & - & - \\
\hline $\begin{array}{l}\text { Atrativos/eventos tu- } \\
\text { rísticos }\end{array}$ & 3 & $\begin{array}{l}\text { Atrativos/eventos tu- } \\
\text { rísticos }\end{array}$ & $16(19)$ & $\begin{array}{l}\text { Atrativos/eventos turísti- } \\
\text { cos }\end{array}$ & $10(2 \circ)$ \\
\hline Beleza & 1 & Beleza & 4 & Beleza & 2 \\
\hline $\begin{array}{l}\text { Características natu- } \\
\text { rais }\end{array}$ & 2 & $\begin{array}{l}\text { Características natu- } \\
\text { rais }\end{array}$ & 10 & Características naturais & $11(19)$ \\
\hline Charme & 1 & Charme & 2 & - & - \\
\hline $\begin{array}{l}\text { Colaboração da comu- } \\
\text { nidade }\end{array}$ & $6(2 \div)$ & $\begin{array}{c}\text { Colaboração da comu- } \\
\text { nidade }\end{array}$ & 8 & $\begin{array}{l}\text { Colaboração da comuni- } \\
\text { dade }\end{array}$ & 2 \\
\hline- & - & $\begin{array}{c}\text { Construções em ex- } \\
\text { cesso (-) }\end{array}$ & 1 & $\begin{array}{c}\text { Construções em excesso } \\
(-)\end{array}$ & 1 \\
\hline Credibilidade & 3 & Credibilidade & 7 & - & - \\
\hline 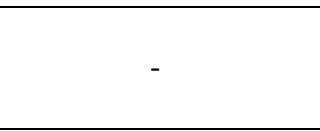 & - & $\begin{array}{l}\text { Eficiência na comple- } \\
\text { mentaridade do pro- } \\
\text { duto turístico }\end{array}$ & 5 & - & - \\
\hline- & - & Elegância & 1 & - & - \\
\hline- & - & Encantadora & 5 & - & - \\
\hline Empreendedorismo & 3 & Empreendedorismo & 1 & - & - \\
\hline- & - & Esgoto (-) & 1 & Esgoto (-) & 1 \\
\hline Gestão pública & 3 & Gestão pública & 2 & - & - \\
\hline Hospitalidade & 4 (4ㅇ) & Hospitalidade & $13\left(2^{\circ}\right)$ & Hospitalidade & 7 (3의) \\
\hline $\begin{array}{l}\text { Imaginário de Gra- } \\
\text { mado como um lugar } \\
\text { não brasileiro }\end{array}$ & 1 & $\begin{array}{l}\text { Imaginário de Gra- } \\
\text { mado como um lugar } \\
\text { não brasileiro }\end{array}$ & $13(29)$ & - & - \\
\hline Infraestrutura geral & 2 & Infraestrutura geral & 4 & Infraestrutura geral & 1 \\
\hline $\begin{array}{l}\text { Infraestrutura/ servi- } \\
\text { ços turísticos }\end{array}$ & $5(3)$ & $\begin{array}{l}\text { Infraestrutura/ servi- } \\
\text { ços turísticos }\end{array}$ & $12(3 \circ)$ & $\begin{array}{c}\text { Infraestrutura/serviços } \\
\text { turísticos }\end{array}$ & 2 \\
\hline Inovação & $7(1 ㅇ)$ & Inovação & $14(19)$ & Inovação & $3(49)$ \\
\hline Limpeza & 2 & Limpeza & 7 & Limpeza & 2 \\
\hline Um pouco caro (-) & 2 & Um pouco caro (-) & 1 & Um pouco caro (-) & 1 \\
\hline Modernidade & 1 & - & - & - & - \\
\hline Organização & 2 & Organização & 3 & Organização & 1 \\
\hline- & - & - & - & $\begin{array}{l}\text { Perda da tranquilidade } \\
(-)\end{array}$ & 1 \\
\hline Produtos de origem & $4(5 \div)$ & Produtos de origem & 5 & Produtos de origem & 2 \\
\hline- & - & Profissionalismo & 4 & Profissionalismo & 2 \\
\hline Qualidade de vida & 2 & Qualidade de vida & 2 & Qualidade de vida & 2 \\
\hline $\begin{array}{l}\text { Qualidade organizaci- } \\
\text { onal }\end{array}$ & 1 & $\begin{array}{c}\text { Qualidade organiza- } \\
\text { cional }\end{array}$ & 5 & - & - \\
\hline Romântica & 1 & Romântica & 1 & - & - \\
\hline Segurança & 3 & Segurança & 6 & Segurança & $3(4 \div)$ \\
\hline
\end{tabular}




\begin{tabular}{|c|c|c|c|c|c|}
\hline Tranquilidade & 1 & Tranquilidade & 4 & Tranquilidade & 3 (4) \\
\hline $\begin{array}{c}\text { Trânsito/ mobili- } \\
\text { dade (-) }\end{array}$ & 1 & $\begin{array}{c}\text { Trânsito/ mobilidade } \\
(-)\end{array}$ & 4 & Trânsito/mobilidade (-) & 2 \\
\hline
\end{tabular}

Fonte: Elaborado pelas autoras

Sobre o atributo com maior frequência na totalidade dos 3 grupos de stakeholders, apareceu atrativos/eventos turísticos, com 29 ocorrências. Esse atributo é destacado pela grande quantidade e pela inovação. São oferecidas opções de visitação e de espetáculos para os turistas o ano todo, de modo a driblar a sazonalidade e de fazer com que fiquem na destinação por muitos dias.

Quanto à inovação dos atrativos/eventos turísticos, considerando-a como a criação de novidade (Johannessen, Olsen \& Lumpkin, 2001), foi focada a tematização dos parques e eventos. Em relação aos parques temáticos, foi muito citado o Snowland (parque de neve artificial). Para exemplificar, expõe-se o relato do sujeito 10 (IP): “[...] os grandes pontos turísticos, o último recente que Gramado inovou é o Snowland, que trouxe pra Gramado uma nova forma de desfrutar da neve, independente se tá 40 graus na rua.". Vargas (2013), em sua dissertação, abordou a tematização em Gramado e, para ela, isso é um modo de alimentar um imaginário de "disneyficação". Vargas revela os parques da Walt Disney World, nos Estados Unidos, influenciam o Natal Luz e o Chocofest. O sujeito 13 (IP) equiparou Gramado com os parques da Disney, devido à tematização dos eventos. Então, a partir do exposto por Vargas, afirma-se que, além de Gramado estar associada ao imaginário de um lugar não brasileiro e ao imaginário de europeização, ainda está vinculada ao imaginário de "disneyficação".

Atrativos/eventos turísticos ainda é aparece como 1 dos atributos (o outro é infraestrutura geral) que diferenciam Gramado dos concorrentes (posicionamento), em resposta à questão 4 (Dos atributos citados, quais diferenciam Gra- mado desses concorrentes?). Os concorrentes citados em resposta à questão 3 (Quais são os principais destinos turísticos concorrentes de Gramado?) são destaques nacionais (Rio de Janeiro, São Paulo e Foz do (guaçu), destino de inverno (Campos do Jordão), e cidades da região (Bento Gonçalves e Canela), segundo os relatos: "[...] único em vários fatores, principalmente, no quesito eventos" (sujeito 3, PP); "O que ele tem é a experiência única [...] de estar num lugar que tem todas as coisas que gostaria, sem contar a parte dos eventos [...]" (sujeito 12, IP); "Natal Luz, que os outros municípios não tão investindo." (sujeito $16, \mathrm{CT})$; "[...] coisas que as outras cidades não têm, [...] o Snowland, [...]" (sujeito 18, CT); e "[...] tem várias atrações. É o ano todo, em cada mês, pelo menos, tem um tipo de atração. Diferente de qualquer lugar." (sujeito 19, CT).

Agora, compara-se os tópicos dos 3 grupos de entrevistados para verificar se há fortes relacionamentos entre a marca e os stakeholders internos. A maioria dos tópicos se repete nos 3 grupos. Aqueles que estão nos relatos de apenas 1 dos grupos são: elegância, eficiência na complementaridade do produto turístico, modernidade, ameaça à preservação, perda da tranquilidade, e encantadora - 20,59\% do total. Ainda, alguns desses tópicos estão nos relatos dos demais grupos de outro modo, como Eficiência na complementaridade do produto turístico (desempenho satisfatório de todos na cadeia turística), citado por 5 sujeitos da iniciativa privada que afirmam que o Poder Público e os empresários fazem sua parte para ter essa eficiência; já os sujeitos do Poder Público citaram a eficiência da gestão pública e dos empresários isoladamente. Alguns exemplos: "[...] a iniciativa privada investe nos estabelecimentos e o Poder Público cuida bem da cidade." 
(sujeito 4, da IP); “Não a prefeitura fazer investimento, mas criou clima pra que o empresariado pudesse fazer." (sujeito 1, do PP); e "Nossa gastronomia é bem diversificada. A nossa hotelaria também, temos mais de 11 mil leitos. Temos a melhor infraestrutura turística do Rio Grande do Sul. As lojas também, elas já têm um contexto qualificado [...]." (sujeito 2, do PP).

Ameaça à preservação, citado pelo sujeito 17 (CT), está associado ao tópico construções em excesso, apontado pelos sujeitos 12 (IP) e 18 (CT), pois ambos referem-se à diminuição da vegetação devido ao crescimento da cidade. Perda da tranquilidade - na alta temporada pelo excesso de pessoas -, apontado apenas pelo sujeito 17 (CT), está associada à tranquilidade - presente em outros períodos - (citada por 1 dos sujeitos do Poder Público, por 4 da iniciativa privada, e por 3 da comunidade local e trabalhadores); e ao trânsito/mobilidade, pois congestionamentos provocam estresse.

Quanto ao público visitante de Gramado - o que também faz parte da personalidade da destinação, no Quadro 2, está a síntese dos elementos citados em resposta à questão 5 (Que tipo de turista frequenta seu estabelecimento e Gramado?). Os elementos estão em ordem alfabética e separados em conjuntos.

Constata-se que quanto ao interesse, à constituição dos grupos e à idade dos turistas, as respostas dos sujeitos dos 3 grupos de stakeholders se semelham. A maioria dos visitantes busca lazer. Recebem-se muitas pessoas que viajam em família e, mais durante o Natal Luz (de outubro a janeiro), bastante grupos através de agência de turismo ou por excursões. As idades são variadas (idosos, adultos e crianças). Adultos ainda participam de congressos/feiras. Em geral, a cidade não é procurada pelos jovens atrás de vida noturna, exceto durante o Festival de Cinema em agosto. Por outro lado, alguns atrativos são procurados por estudantes, como o Gramado Zoo.
Há divergências com relação às classes sociais dos visitantes. Foram citadas diversas classes sociais, estando em consenso com o sujeito 2 (PP) ao contar que o marketing da destinação não é direcionado a um público específico quanto à classe social. Busca-se atrair turistas de classes mais altas ao, por exemplo, elaborar materiais gráficos que remetam ao luxo e criar uma grife de souvenirs de alta qualidade; em paralelo, buscase mostrar para outro público (subentende-se excursionistas - aqueles que não pernoitam) que há muito a fazer em Gramado e que não há só meios de hospedagem de preço elevado, para que fiquem mais dias e usem o trade turístico.

Parece ser também essa a postura de outros gestores públicos, segundo o sujeito 13 (IP), que afirmou já terem sido autorizados planos de novos meios de hospedagem na cidade os quais propõem a construção de 9 mil leitos, nos próximos 5 anos, o que, para ele, resulta em um alto acúmulo de pessoas, afugentando aquelas de classes AA, A e B. Na reportagem de Mariano (2013) consta que, naquele ano, havia 25 planos de hotéis e pousadas na mesa do prefeito à espera de aprovação, sendo que apenas os dois empreendimentos maiores previam mais 5 mil leitos na destinação - quase a metade do total de leitos até então. Na época, foi decidido pela não aprovação de novos hotéis com mais de 30 unidades habitacionais por um prazo de 90 dias, pois se acreditava que o excesso de projetos causaria impactos a médio e longo prazo, já sendo notados alguns problemas. Os problemas eram: congestionamentos no centro e nos acessos à cidade; falta de estacionamento; filas nos restaurantes nos fins de semana; descaracterização da destinação com o acúmulo de prédios; e o alto número de leitos ociosos nos dias úteis na baixa temporada (em torno de 40\%). Com a moratória, reestudar-se-ia o Plano Diretor, formando uma comissão de especialistas para propor regras e consultar o Conselho do Plano (do qual fazem 
parte algumas entidades de classe da área do turismo e alguns membros de associações de bairro).

Quadro 2 - Síntese do público visitante de Gramado conforme apontado pelos entrevistados

\begin{tabular}{|c|c|c|c|c|c|c|}
\hline & \multicolumn{2}{|c|}{ Poder Público } & \multicolumn{2}{|l|}{ Iniciativa privada } & \multicolumn{2}{|c|}{$\begin{array}{c}\text { Comunidade local e tra- } \\
\text { balhadores }\end{array}$} \\
\hline & Tópicos & Freq. & Tópicos & Freq. & Tópicos & Freq. \\
\hline \multirow{3}{*}{ 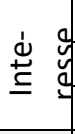 } & Congressos/feiras & 2 & Congressos/feiras & 4 & Congressos/feiras & 1 \\
\hline & Lazer & 3 & Lazer & 11 & Lazer & 5 \\
\hline & Lua de mel & 2 & Lua de mel & 6 & Lua de mel & 1 \\
\hline \multirow{3}{*}{ 仓ั } & Familiar & 3 & Familiar & 9 & Familiar & 5 \\
\hline & Por agência & 1 & Por agência & 4 & Por agência & 2 \\
\hline & Por excursão & 1 & Por excursão & 1 & Por excursão & 4 \\
\hline \multirow{5}{*}{$\begin{array}{l}\frac{0}{0} \\
\frac{\pi}{0}\end{array}$} & Crianças & 1 & - & - & Crianças & 1 \\
\hline & - & - & Jovens & 2 & Jovens & 1 \\
\hline & - & - & Público maduro & 3 & Público maduro & 1 \\
\hline & Terceira idade & 1 & Terceira idade & 3 & Terceira idade & 1 \\
\hline & - & - & - & - & Todas as idades & 2 \\
\hline \multirow{9}{*}{$\begin{array}{l}\overline{\frac{\pi}{U}} \\
0 \\
心 \\
\mathbb{N} \\
\widetilde{N} \\
\frac{0}{U}\end{array}$} & $A, B, C$ e $D$ & 1 & - & - & - & - \\
\hline & - & - & $A, B$ e $C$ & 1 & $A, B$ e $C$ & 3 \\
\hline & - & - & $\mathrm{B}$ e C & 2 & - & - \\
\hline & Massificando & 1 & Massificando & 1 & - & - \\
\hline & - & - & $\begin{array}{l}\text { Mudança de perfil. } \\
\text { Há pouco tempo, recebia- } \\
\text { se diversas classes. Baixa } \\
\text { na qualidade pode não } \\
\text { atrair as classes altas }\end{array}$ & 1 & - & - \\
\hline & - & - & $\begin{array}{l}\text { Mudança de perfil. Possi- } \\
\text { bilidade do público AA, A e } \\
\text { B fugirem do tumulto }\end{array}$ & 1 & - & - \\
\hline & - & - & $\begin{array}{l}\text { Participantes de congres- } \\
\text { sos/feiras com um nível de } \\
\text { renda mais alto (A e B) }\end{array}$ & 1 & - & - \\
\hline & - & - & $\begin{array}{l}\text { Poder aquisitivo baixo du- } \\
\text { rante os grandes eventos }\end{array}$ & 1 & - & - \\
\hline & $\begin{array}{l}\text { Todas/diversas } \\
\text { classes sociais }\end{array}$ & 1 & $\begin{array}{c}\text { Todas/diversas clas- } \\
\text { ses sociais }\end{array}$ & 2 & $\begin{array}{l}\text { Todas/diversas } \\
\text { classes sociais }\end{array}$ & 2 \\
\hline
\end{tabular}

Fonte: Elaborado pela autora.

Voltando às declarações do sujeito 13 , ele expõe que o público $A A, A$ e $B$ busca qualidade nos serviços, ameaçada pelo alto aumento de leitos, que pode obrigar os hotéis atuais a baixarem os preços. Dessa forma, para esse sujeito, a tendência é que só os visitantes que gastam pouco continuem a frequentar a cidade e em alto número:

Existe um projeto de 300 apartamentos para dividir cada um deles em 12 quotas. Faz 300 vezes 12 pra ver quanta gente é. $\mathrm{E}$ esses apartamentos possuem cozinha. Então, primeiro, essas pessoas não vêm para um hotel; segundo, vai diminuir aqueles 
que vão pra rua comer. [...] 300 famílias por vez que só vão contribuir com compras no mercado. Não é a mesma coisa que se tu fizer o custo-benefício do que eles custam a mais pra cidade e nós é que vamos estar subsidiando boa parte do que eles consumirão do serviço público.

Isso monstra que o marketing não se limita à promoção, conforme afirma Keller \& Machado (2006), incluindo estratégias de produto, preço e praça convergentes com o divulgado. Uma estratégia de produto já cogitada pelo viceprefeito de Gramado para a competitividade dos meios de hospedagem em um mercado com excesso de oferta é o investimento em hotéis inovadores, com tematização ou instalando-os na zona rural (Mariano, 2013). Isso está de acordo com a estratégia de diferenciação de Porter (1989): fazer de um produto único em um mercado por meio de uma característica peculiar, da imagem, do suporte e em uma variedade de outros fatores.

Sobre os excursionistas, o sujeito 17 (CT) revela que há descontentamento por parte das pessoas em Gramado quanto ao grande número deles durante o Natal Luz, devido a seus baixos gastos. Contudo, ainda o sujeito 17 acredita que mesmo as classes mais baixas propiciam benefícios ao destino. O sujeito 12 (IP) confirma: "O Chocofest foi muito criticado porque os empresários dizem, não são todos, que a Chocofest não atrai cliente com poder aquisitivo bom. O mesmo está acontecendo com o Natal Luz." Também o sujeito 12 se manifesta 2 vezes sobre a necessidade de um planejamento estratégico que envolva os stakeholders e, em um dos seus relatos, coloca como condição para resolver os problemas de mobilidade: "Não existe um planejamento estratégico, as coisas vão acontecendo. Instituir valores pra circulação de ônibus, pra [...], enfim. A cidade é pequena e, às vezes, não comporta todo esse público. Algumas coisas tão de consenso e outras não. Não existe unanimidade.".

O entrevistado percebe a importância de haver consenso entre os stakeholders quanto ao público-alvo da destinação, o que faz parte da identidade de marca e está ligado a outras características da identidade, como a mobilidade. Isso porque, como afirma Buhalis (2000), uma destinação é uma amálgama de produtos e serviços que proporciona uma experiência total aos turistas; então, se cada componente transmitir uma identidade diferente, isso repercutirá na percepção dos visitantes sobre a experiência total. E por isso, Hankinson (2004) afirma que a rede de relacionamentos deve ser formada durante todo o processo de construção da identidade de marca, ou seja, deve incluir seu planejamento - o que é citado pelo sujeito 12 (IP) -, seu preparo e sua operacionalização. Como uma destinação é complexa em público e stakeholders envolvidos, em que cada consumidor é livre para escolher os elementos a consumir (não se pode controlar o "produto experiência" igual a um produto manufaturado), é preciso que o branding seja um processo coordenado, não gerenciado, de forma que os stakeholders tenham papel proativo na construção da identidade de marca.

Segundo sujeitos da Secretaria de Turismo, há um Plano Municipal de Turismo; porém, esse plano não é satisfatório. Outra informação relevante sobre o relacionamento dos stakeholders é que, além da existência de um Conselho de Turismo vinculado à Secretaria, há um Conselho de Administração da Gramadotur (responsável pelos principais eventos turísticos da destinação), do qual fazem parte representantes da iniciativa privada. Porém, conforme sujeito 3 (PP), a função deste conselho está mais atrelada à assessoria financeira, não tanto à parte organizacional.

Apesar de haver muitas semelhanças com relação aos atributos citados pelos entrevistados, percebem-se significativas divergências 
entre os stakeholders internos quanto ao público visitante, demonstrando que há fragilidades nos relacionamentos entre eles. Isso reflete a falta de um planejamento estratégico. Desse modo, cada um faz aquilo que estabelece como sua parte, mas, no geral, não de forma conjunta.

O que se está expondo não é o julgamento sobre se é melhor atrair visitantes de classes mais altas ou baixas, mas o conflito que pode haver, e que já está ocorrendo de algum modo, principalmente, no que tange à alta temporada, entre as características da identidade de marca de Gramado, o que é decorrente da falta de uma definição precisa do público-alvo. Para Hankinson (2004), uma destinação não deve atrair grupos de visitantes com necessidades conflitantes, como, por exemplo, não atrair para uma destinação movimentada pessoas que buscam tranquilidade. Ainda, definir o público é relevante para a tomada de decisões referente a outras características da identidade de marca, que, em Gramado, são: a qualidade de infraestrutura/serviços turísticos; o preço; a infraestrutura geral, afeto à mobilidade; e as características naturais, ligadas ao excesso de construções e ao crescimento acelerado que tem destruído a vegetação.

No entanto, nota-se que a definição precisa do público visitante é uma situação difícil, em se tratando de destinações turísticas, visto as diferentes naturezas dos stakeholders envolvidos. Empresas têm mais flexibilidade para escolher o seu público-alvo, sendo que a lucratividade pode provir tanto da quantidade como da qualidade dos serviços. Isso porque as organizações têm o direito à livre iniciativa, presente na Constituição Federal do Brasil (1988); a qual Gomes (2008) conceitua como a garantia de todos à livre criação de organização empresarial e à sua gestão, de forma autônoma, o que inclui a liberdade de determinar como será desenvolvida a atividade, abarcando a forma, qualidade, quantidade e o preço dos seus produtos ou serviços. Já os governantes têm um papel social maior, não podem limitar suas escolhas à lucratividade que os turistas propiciam à destinação e à consequente maior arrecadação de impostos para o bem-estar da população e dos turistas. Seu papel vai além do bem-estar da sociedade onde atuam e, conforme o art. 23 da Constituição Federal/88: "É competência comum da União, dos Estados, do Distrito Federal e dos Municípios: $\mathrm{X}$ - combater as causas da pobreza e os fatores de marginalização, promovendo a integração social dos setores desfavorecidos". Por isso, uma destinação deve ser receptiva a todos turistas. Ainda, a existência de eventos populares, como o Natal Luz, contribui muito para a formação da imagem de Gramado como "destino turístico modelo" e torna a destinação competitiva perante o litoral durante o verão.

No Quadro 3, os tópicos são divididos em categorias (atributos funcionais, atributos simbólicos, atributos experienciais e atributos organizacionais), definidas a partir de Hankinson (2004) e de Aaker (1996), e em suas respectivas subcategorias.

Constata-se que os stakeholders de Gramado associam à imagem de "destino turístico modelo", sobretudo, os atributos simbólicos (138 ocorrências, $35,57 \%$ ) e os atributos funcionais (111 ocorrências, 28,61\%). A diferença percentual entre essas categorias de atributos não chega a $10 \%$. Já a soma dos percentuais das categorias atributos organizacionais (76 ocorrências, $19,59 \%$ ) e atributos experienciais (63 ocorrências, $16,24 \%$ ) resulta em $35,83 \%$, não atingindo $1 \%$ de diferença da categoria atributos simbólicos. Isso mostra a relevância das categorias com maior percentual na construção da identidade de marca de Gramado. É natural que a categoria atributos simbólicos seja aquela com maior frequência, pois, para Norberto (2007), a marca está inscrita em um campo simbólico. Isso porque, como a autora já relatou em 2004, as marcas permitem que a utilidade de um produto não se limite a suas propriedades funcionais, incluindo os mundos de significações incorporados a esse. 
Quadro 3 - Divisão categorial dos atributos da destinação

\begin{tabular}{|c|c|c|}
\hline Categorias & Subcategorias & Freq. \\
\hline \multirow{11}{*}{$\begin{array}{l}\text { Atributos } \\
\text { Simbólicos }\end{array}$} & Hospitalidade/atendimento (+) & 24 \\
\hline & Lazer & 19 \\
\hline & Todas as classes sociais & 18 \\
\hline & Grupo familiar & 17 \\
\hline & Imaginário de não Brasil (+) & 14 \\
\hline & Crianças, adultos e idosos & 11 \\
\hline & Lua de mel & 9 \\
\hline & Congressos/feiras & 7 \\
\hline & Grupos por agência & 7 \\
\hline & Grupos por excursão & 6 \\
\hline & Imaginário de europeização (+) & 6 \\
\hline \multirow{10}{*}{$\begin{array}{l}\text { Atributos } \\
\text { Funcionais }\end{array}$} & Atrativos/eventos turísticos (+) & 29 \\
\hline & \begin{tabular}{c|c} 
Características naturais (+) & $\begin{array}{c}\text { Vegetação, clima, relevo, Lago Negro, zona ru- } \\
\text { ral, etc. }\end{array}$ \\
\end{tabular} & 23 \\
\hline & Infraestrutura/serviços turísticos (+) & 19 \\
\hline & Produtos de origem (+) & 11 \\
\hline & Rede de transporte/trânsito/mobilidade & 7 \\
\hline & Rede de esgoto & 2 \\
\hline & Ambiente dos bairros, calçadas, flores, etc. & 7 \\
\hline & Arquitetura (+) & 6 \\
\hline & Lugar um pouco caro $(+)$ & 4 \\
\hline & $\begin{array}{c}\text { Vegetação/construções em excesso e ameaça à } \\
\text { preservação }\end{array}$ & 3 \\
\hline \multirow{8}{*}{$\begin{array}{l}\text { Atributos Or- } \\
\text { ganizacionais }\end{array}$} & Inovação (+) & 24 \\
\hline & Colaboração da comunidade (+) & 16 \\
\hline & Credibilidade $(+)$ & 10 \\
\hline & Profissionalismo (+) & 6 \\
\hline & Qualidade organizacional (+) & 6 \\
\hline & Eficiência na complementaridade do produto turístico (+) & 5 \\
\hline & Gestão pública (+) & 5 \\
\hline & Empreendedorismo (+) & 4 \\
\hline \multirow[t]{8}{*}{$\begin{array}{c}\text { Atributos Ex- } \\
\text { periênciais }\end{array}$} & Segura (+) & 12 \\
\hline & Limpa (+) & 11 \\
\hline & Tranquila (+) & 8 \\
\hline & Bela (+) & 7 \\
\hline & Organizada (+) & 6 \\
\hline & Qualidade de vida (+) & 6 \\
\hline & Encantadora (+) & 5 \\
\hline & Charmosa (+) & 3 \\
\hline
\end{tabular}




\begin{tabular}{|c|c|c|}
\hline & Romântica (+) & 2 \\
\cline { 2 - 3 } & Elegante (+) & 1 \\
\cline { 2 - 3 } & Moderna (+) & 1 \\
\cline { 2 - 3 } & Perda da tranquilidade (-) & 1 \\
\hline
\end{tabular}

Fonte: Elaborado pelas autoras.

Percebeu-se que há uma intrínseca relação entre os atributos simbólicos e os atributos funcionais quanto à definição do público-alvo (atributo simbólico). Isso, porque, como já exposto, tal definição repercute nas decisões referentes a outras características da identidade de marca de Gramado, como qualidade de infraestrutura/serviços turísticos, preço, infraestrutura geral e características naturais, que são atributos funcionais.

\section{CONSIDERAÇÕES FINAIS}

Foi constatado que se busca gerar a imagem de Gramado como "destino turístico modelo", através da construção da sua identidade de marca. Tal identidade é formada por $34 \mathrm{com}$ ponentes distintos. $\mathrm{O}$ atributo que mais aparece na totalidade dos 3 grupos de stakeholders entrevistados é atrativos/eventos turísticos, com 29 ocorrências. Esse atributo ainda aparece como destaque na diferenciação de Gramado frente a seus concorrentes (posicionamento) - que, em geral, são destinos turísticos brasileiros.

Os atributos foram divididos em 4 categorias. As categorias mais representativas foram: atributos simbólicos $(35,57 \%)$ e atributos funcionais $(28,61 \%)$, acompanhados por atributos organizacionais e atributos experienciais em menor escala.

Também, foi verificado que há fragilidades nos relacionamentos entre os stakeholders internos. Essa verificação foi feita pela comparação entre os tópicos citados pelos 3 grupos de stakeholders, em que se percebeu divergências, principalmente, no que se refere às classes sociais dos visitantes. Foi constatado que, atualmente, o marketing de Gramado não é direcionado para nenhum público-alvo específico quanto à classe social, sendo visitada por públicos diversos. Entretanto, alguns sujeitos gostariam que houvesse um direcionamento para os públicos $A A, A$ e $B$, enquanto outros não consideram uma restrição. Ainda, um dos entrevistados apontou a falta de um planejamento estratégico em que seria definido o público-alvo. Essa divergência repercute em um conflito entre as características da identidade de marca da destinação, como, por exemplo, entre massificação e qualidade em infraestrutura/serviços turísticos. Por isso, é relevante que haja uma definição mais precisa do público visitante. Porém, nota-se que essa definição é uma situação difícil, tratando-se de destinos turísticos, visto as diferentes naturezas dos stakeholders.

Podem ser destacadas algumas contribuições desta pesquisa para o conhecimento sobre identidade de marca de destinações turísticas: 1) a identificação de dificuldades na definição de público quanto à marca-destinação, devido às diferentes naturezas dos stakeholders envolvidos, o que demonstra uma significativa distinção desse tipo de marca com relação à marca geral; 2) além dos atributos funcionais, simbólicos e experienciais - adotados por Hankinson (2004) -, foram detectados atributos organizacionais, como parte da marca-destinação, tendo também sua importância na construção desse tipo de marca. São contribuições singelas e que apontam a necessidade de outras pesquisas que avancem sobre elas. Assim, sugere-se que se pesquise mais sobre a definição de público, de modo 
a levar reflexões mais profundadas sobre a problemática. Dessa forma, esta pesquisa não se encerra em si; mostra novos caminhos a serem percorridos nessa área do conhecimento.

\section{REFERÊNCIAS}

Aaker, D. A. (1996). Criando e administrando marcas de sucesso. São Paulo: Futura.

Bahl, M. (2004). Legados étnicos \& oferta turística. Curitiba: Juruá.

Bardin, L. (2004). Análise de Conteúdo. 3. ed. Lisboa: Edições 70.

Buhalis, D. (2000). Marketing the competitive destination of the future. Tourism Management, (21), 97-116.

Constituição da República Federativa do Brasil de 1988. (1988). Brasília. Recuperado em 30 nov, 2014, de http://www.planalto.gov.br/ccivil_03/Constituicao

\section{/Constituicao.html}

De Chernatony, L. (1999). Brand management through narrowing the gap between brand identity and brand reputation. Journal of Marketing Management, (15), 157-179.

Goldenberg, M. (2004). A arte de pesquisar: como fazer pesquisa qualitativa em Ciências sociais. 8. ed. Rio de Janeiro: Record.

Gomes, C. J. V. (2008). Constituição de 1988: o Brasil 20 anos depois - Estado e economia em vinte anos de mudanças (v. 4). Brasília:Senado Federal.

Hankinson, G. (2004). Relational network brands: towards a conceptual model of place brands. Journal of Vacation Marketing, 10 (2), 109-121.

Hankinson, G. (2007). The management of destination brands: Five guiding principles based on recent developments in corporate branding theory. Journal of Brand Management, 14 (3), 240-254.

Johannessen, J. A., Olsen, B. \& Lumpki, G.T. (2001). Innovation as newness: what is new, how new, and new to whom? European Journal of Innovation Management, 4 (1), 20-31.

Karamarko, N. (2010). System of tourist destination management as a Croatian identity. Tourism \& Hospitality Management - Conference Proceedings, 950966.
Keller, K. L. \& Machado, M. (2006). Gestão estratégica de marcas. São Paulo: Pearson Education do Brasil.

Kotler, P. (1997). Marketing management: analysis, Planning, Implementation, and Control. 9. ed. Upper Saddle River, NJ: Prentice-Hall.

Kotler, P. (2009). Marketing para o século XXI: como criar, conquistar e dominar mercados. São Paulo: Ediouro.

Kotler, P. \& Gertner, D. (2002). Country as brand, product, and beyond: a place marketing and brand management perspective. Journal of Brand Management, 9 (4), 249-261.

Mariano, N. (2013, 3 de agosto). Gramado enfrenta sintomas de esgotamento. Zero Hora. Recuperado em 23 out, 2013, de http://zerohora.clicrbs.com.br/rs/economia/empregos-e-carreiras/noticia/2013/ 08/gramado-enfrenta-sintomas-de-esgotamento-4222541.html

Meler, M. \& Ruzic, D. (1999). Marketing identity of the tourist product of the Republic of Croatia. Tourism Management, 20, 635-643.

Ministério do Turismo - Mtur. (2008). Relatório final do Vivências Brasil: aprendendo com o turismo nacional 2008/2009 - etapa Serra gaúcha. Brasília: MTur.

Ministério do Turismo - Mtur. (2010). Caderno de subsídios: eventos como solução criativa contra a sazonalidade 2010. Brasília: MTur.

Norberto, E. (2004). Estratégias corporativas de marcas e estratégias sociais de diferenciação: uma análise a partir do automóvel. Tempo Social, 16 (2), 203-208.

Parkerson, B. \& Saunders, J. (2005). City branding: Can goods and services branding models be used to brand cities? Place Branding, 1 (3), 242-264.

Pimentel, E., Pinho, T. \& Vieira, A. (2006). Imagem da marca de um destino turístico. Turismo - Visão e Ação, $8(2), 283-298$.

Porter, M. E. (1989). Vantagem competitiva: criando e sustentando um desempenho superior. Rio de Janeiro: Campus.

Prefeitura Municipal de Gramado - PMG. (2008). Gramado e Óbidos unidas pelo turismo. Recuperado em 7 jul, 2013, de http://www.gramado.rs.gov.br/index.php/Gramado-e-Obidos. html

Prefeitura Municipal de Gramado - PMG. (2013a). Comitiva de Bragança Paulista visita Gramado. Recupe- 
rado em 7 jul, 2013, de http://www.gramado.rs.gov.br/index.php/ Institucionais/Comitivade-Braganca- Paulista-visita-Gramado.html

Prefeitura Municipal de Gramado - PMG. (2013b). Embaixador da Nigéria visita Gramado. Recuperado em 7 jul, 2013, de http://www.gramado.rs.gov.br/index.php/Institucionais/ Embaixador-da-Nigeria-visitaGramado.html

Prefeitura Municipal de Gramado - PMG. (2013c). Nestor recebe comitiva chilena. Recuperado em 7 jul, 2013, de http://www.gramado.rs.gov.br/index.php/Institucionais/Nestor-recebe-comitiva-chilena.html

Prefeitura Municipal de Gramado - PMG. (2013d). Gramado concorre mais uma vez a 'Melhor Destino de Inverno' do Brasil. Recuperado em 9 dez, 2013, de http://www.gramado.rs.gov.br/ index.php/Turismo/Gramado-concorre-mais-uma-vez-a-MelhorDestino-de-Inverno-do-Brasil. html

Prefeitura Municipal de Gramado - PMG. (2014a). Nestor recebe o Prefeito de Iguape (SP). Recuperado em 7 fev, 2014, de http://www.gramado.rs.gov.br/index.php/Institucionais/ Nestor-recebe-o-Prefeito-deIguape-SP.html.

Prefeitura Municipal de Gramado - PMG. (2014b). Gramado recebe visita de comitiva de Ourinhos-SP. Recuperado em 3 mar, 2014, de http://www.gramado.rs.gov.br/index.php/ Turismo/-Gramado-recebe-visita-de-comitiva-de-Ourinhos-SP.html

Reynolds, W. (1965). The role of the consumer in image building. California Management Review, (7), 6976.
Secretaria Municipal de Comunicação e Eventos - Secom. (2013). Prefeitura de Caldas Novas encaminha comitiva à Gramado para estudar modelo de turismo. Recuperado em 10 jul, 2013, de http://www.caldasnovas.go.gov.br/prefeitura-de-caldas-novas-encaminhacomitiva-a-gramado-para-estudar-modelo-de-turismo/

Vargas, D. P. (2013). Turismo e Imaginário: o percurso histórico do chocolate em Gramado/RS (Dissertação de Mestrado em Turismo). Universidade de Caxias do Sul.

Yin, R. K. (2010). Estudo de caso: planejamento e métodos. 4. ed. Porto Alegre: Bookman.

\section{Dados dos Autores}

\section{Vanessa Acosta de Azambuja}

Mestre em Turismo pelo Programa de Pós-Graduação em Turismo da Universidade de Caxias do Sul - UCS. Bacharel em Turismo pela Universidade Federal de Pelotas - UFPEL. E-mail: turismologa.vanessa@yahoo.com.br

\section{Marlei Salete Mecca}

Universidade de Caxias do Sul - Doutora em Engenharia de Produção pela Universidade Federal de Santa Catarina - UFSC. Bacharel em Administração e em Ciências Contábeis. Professora do Programa de Pós-Graduação em Turismo e do Curso de Ciências Contábeis da Universidade de Caxias do Sul - UCS. E-mail: msmecca@ucs.br 